\title{
Investigando Interações Discursivas em Aulas de Ciências: Um “Olhar Sensível ao Contexto" sobre a Pesquisa em Educação em Ciências
}

\section{Investigating Discursive Interactions in Science Lessons: "Contextual Lenses" on Research in Science Education}

\author{
Luiz Gustavo Franco ${ }^{\circledR}$ Brasil \\ Danusa Munford ${ }^{\circledR}$ Brasil
}

Apresentamos uma discussão crítica em torno do construto teórico-metodológico contexto na pesquisa que investiga interações discursivas em aulas de ciências. Baseados na noção de que contextos são históricos, múltiplos e interativos, entendemos que a pesquisa pode valorizar contextos em diferentes níveis. Utilizando um amplo conjunto de artigos desenvolvidos nos anos iniciais do Ensino Fundamental, selecionamos oito exemplos considerados ilustrativos para fundamentar nossa discussão. Desenvolvemos um "olhar sensível ao contexto" para caracterizar diversas formas de valorização do contexto, desde níveis mais locais (instrucional e da sala de aula), até níveis mais amplos (institucional, comunitário, social e cultural). Destacamos o potencial de um enfoque mais descritivo na pesquisa em EC no sentido de valorizar contextos que vão além da sala de aula.

Palavras-chave: contexto; discurso em sala de aula; pesquisa em Educação em Ciências.

We present a critical discussion about context as a theoretical-methodological construct on research that investigates discursive interactions during science lessons. Based on the notion that context is historical, multiple and interactive, we understand that research can focus on different levels of context. We used a wide range of articles about the early years of Elementary School, selecting eight examples considered illustrative to ground our discussion. Developing "contextual lenses" we characterize the diverse ways to consider context, from the more local level (instructional and classroom), to a broader level (institutional, community, social and cultural). We point the potential of a more descriptive focus in Science Education research in the sense of highlighting contexts that go beyond the instruction.

Keywords: context; classroom discourse; Science Education research. 


\section{Introdução}

O objetivo do presente artigo é apresentar um ensaio crítico sobre "contexto" enquanto construto teórico-metodológico nas pesquisas que investigam interações discursivas na área de Educação em Ciências (EC). Nas últimas décadas, uma gama de pesquisadores das ciências humanas tem buscado se apropriar de noções de contexto desenvolvendo análises preocupadas em ir além de seus objetos de estudo em si mesmos e construir relações com aspectos contextuais em que esses objetos estão imersos (ver Bloome et al., 2008; Goodwin, \& Duranti, 1992).

$\mathrm{Na}$ área de $\mathrm{EC}$, por sua vez, também é considerado relevante levar em conta elementos contextuais. Uma preocupação central nessa direção é o desenvolvimento de um ensino contextualizado (ver a discussão de Bennett, Lubben, \& Hogarth, 2007). Autores como Lemke (2001) e Gilbert (2014) defendem que, se a ciência é um empreendimento relacionado a diversos contextos, também o ensino de ciências deve refletir essas relações. Um ensino contextualizado também seria uma potencial alternativa para superarmos noções fragmentadas de conhecimento, presentes em abordagens tradicionais; além de ser capaz de despertar o interesse dos estudantes ao abordar contextos que lhes são familiares (Gilbert, 2014).

Nesse sentido, temos observado iniciativas que estimulam um ensino de ciências capaz de contemplar o contexto em que os estudantes estão inseridos, por exemplo, os programas context-based science teaching (Ramsden, 1997; Gilbert, 2014) e o programa dos perfis conceituais (Mortimer, Scott, Amaral, \& El-Hani, 2014). Nesses casos, o foco é pensar na valorização do contexto como algo que contribui diretamente na melhoria do ensino de ciências nas escolas.

Porém, o objetivo do presente artigo vai em outra direção. Nosso enfoque não é a discussão do contexto como uma estratégia de ensino, mas como um construto teóricometodológico na área de EC, especificamente nos estudos que investigam interações discursivas em sala de aula. Há um amplo interesse dessa área no estudo de interações discursivas em sala de aula (Lin, Lin, \& Tsai, 2014) e a relevância das relações entre essas interações e os contextos nos quais acontecem é reconhecido (Lemke, 2001). Entendemos que aspectos contextuais devem ser valorizados nessas investigações, uma vez que, o que acontece em uma aula de ciências só é possível porque

Todos nós crescemos e vivemos dentro de organizações sociais de maior escala, ou instituições: família, escola, igreja, centro comunitário, laboratório de pesquisa, universidade, corporação, e (dependendo da sua teoria em particular), talvez, também cidade, estado, economia global, e até mesmo uma sala de bate papo ou discussão na Internet que, potencialmente, abrange todo o globo. Nossas vidas nessas instituições e suas comunidades associadas nos dão ferramentas para produzirmos sentido sobre e para aqueles que nos rodeiam: línguas, convenções pictóricas, sistemas de crenças, sistemas de valores e discursos especializados e práticas (Lemke, 2001, p 296).

Desconsiderar esses contextos que perpassam a vida humana ao analisar como estudantes e professores interagem em sala de aula significa abdicar de aspectos 
fundamentais na compreensão sobre como eles negociam, compartilham e constroem o conhecimento em aulas de ciências (Kelly, 2005). Nesse sentido, Lemke (2001) indica que a pesquisa em EC tem buscado agregar contribuições teórico-metodológicas das ciências humanas para reconhecer o papel de elementos contextuais no ensino e aprendizagem de ciências.

Apesar desse reconhecimento, a área de EC, bem como outros campos das ciências humanas, por vezes tem dificuldades em valorizar elementos do contexto dos fenômenos que estudam. Um desafio que persiste é a herança que essas áreas receberam do "modo de fazer ciência" próprio das ciências naturais que preza por investigações context-free (Milsher, 1979), isto é, buscam compreender um fenômeno com a mínima vinculação a aspectos contextuais, o que seria necessário para viabilizar processos de generalização.

Além disso, indicamos outras situações desafiantes para o avanço na pesquisa em EC, por exemplo, a vinculação entre contexto e setting, e as relações entre contexto e os resultados das pesquisas. Muitos pesquisadores da área de $\mathrm{EC}$, ao abordarem o contexto de suas pesquisas, mencionam características como o espaço físico da sala de aula e os sujeitos de pesquisa envolvidos. Alguns deles, principalmente autores internacionais, também mencionam elementos demográficos dos grupos investigados, como gênero, raça e classe (por exemplo, Manz, \& Renga, 2017; Monteira, \& Jiménez-Aleixandre, 2015; Naylor, Keogh, \& Downing, 2007; Oliveira, Akerson, \& Oldfield, 2012; Ryu, \& Sandoval, 2012; Upadhyay, 2009).

Porém, essa caracterização acaba ocupando um lugar secundário nas análises, como um pano de fundo ou cenário. Assim, apesar de reconhecerem certos elementos contextuais, uma análise mais aprofundada sobre como esses elementos influenciaram os resultados obtidos ou auxiliaram na interpretação desses resultados é limitada. Dessa forma, parece-nos importante que a pesquisa possa refletir sobre a complexidade das noções de contexto, entendido para além do setting em que a pesquisa acontece. Para isso, buscamos contribuições em estudos do campo da Linguagem para uma discussão mais fundamentada (Bloome et al., 2008; Blommaert, 2015; Erickson, 2008).

Levar em conta o contexto no qual interações discursivas acontecem é algo consolidado no campo da Linguagem (ver Goodwin, \& Duranti, 1992; Rex, Green, \& Dixon, 1998). Mesmo havendo modos distintos de considerar o construto contexto, é consenso que as análises de interações discursivas envolvam uma "justaposição fundamental de duas entidades: (1) um evento focal; e (2) o campo de ação no qual o evento está embebido" (Goodwin, \& Duranti, 1992, p. 3). Apesar disso, ainda há tensões relacionadas a questões metodológicas sobre o uso do construto contexto no campo da Linguagem.

Essas tensões e as discussões que emergem a partir delas podem contribuir para a área de EC, na medida em se trata de um debate mais aprofundado e gera discussões que nos ajudam a refletir criticamente se e como a área de EC tem se apropriado do uso do construto contexto. Por exemplo, Goodwin e Duranti, (1992) discutem a diversidade de 
formas que o construto contexto é entendido por diferentes tradições da Linguagem. Da mesma forma, podemos nos questionar como nós, pesquisadores em EC, entendemos este construto e como nossas definições estão afiliadas a determinadas tradições teóricometodológicas. Warriner e Anderson (2016), por sua vez questionam quais são as implicações metodológicas das diferentes definições de contexto; o que pode nos levar a pensar sobre como a EC usa metodologias distintas para análise de interações discursivas e quais as suas implicações para as relações com o construto contexto. Erickson (2008), pensando também em questões metodológicas, discute que elementos devem ganhar maior visibilidade ao se considerar contexto: aspectos mais locais das interações ou mais globais? Do mesmo modo, poderíamos nos questionar sobre o quanto as pesquisas em EC geram, metodologicamente, olhares que destacam o contexto imediato das interações ou padrões mais amplos para explicar o que acontece em sala de aula. Blommaert (2015) também oferece uma interessante discussão sobre como tornar as relações entre discurso e contexto mais complexas do que uma mera justaposição unidirecional. Isto é, como considerar a diversidade de fatores que se articulam de modo multidimensional quando as pessoas interagem discursivamente? Haveria pesquisas em EC que levam tais articulações em consideração? Como esses estudos analisam interações discursivas?

No presente artigo estamos especificamente interessados em compreender como pesquisas em EC que trabalham com o estudo de interações discursivas dão maior ou menor visibilidade a diferentes contextos presentes em sala de aula.

Aprofundando discussões anteriores (Munford, Souto, \& Coutinho, 2014), propomos um 'olhar sensível ao contexto' para nos auxiliar a pensar sobre o que tem sido valorizado nas pesquisas e quais as implicações disto para a área. Para isso buscamos responder à questão: quais diferentes níveis de contexto são valorizados nas pesquisas que investigam a interações discursivas em aulas de ciências nos anos iniciais do Ensino Fundamental?"

Trilhamos o seguinte caminho metodológico: inicialmente, buscamos compreender o construto contexto no campo da Linguagem. Construímos uma visão ampla das diferentes definições e usos de "contexto" nesse campo e selecionamos uma delas a fim de desenvolver o que chamamos de um "olhar sensível ao contexto" sobre a pesquisa na área de EC. Nos apropriamos das discussões de Bloome e Green (1982) sobre contexto. Esses autores compreendem que o que acontece em sala de aula está inserido em um contexto mais amplo e que o pesquisador, ao analisar interações neste espaço, dá visibilidade a esse contexto de diferentes formas, dependendo de seus objetivos de pesquisa e metodologias de análise. Essa consideração pareceu-nos importante para que pudéssemos compreender como a pesquisa em EC, por meio de suas diferentes metodologias, daria destaque ao contexto em suas análises.

Bloome e Green (1982) propõem uma visão de contexto em múltiplos níveis. Nesta proposta, o pesquisador pode levar em consideração diferentes níveis de contexto: desde elementos mais locais das interações; por exemplo, características da sala de aula investigada, a formação do professor da turma e as atividades desenvolvidas em 
uma sequência de aulas; até aspectos mais globais, como as políticas educacionais que orientam aquela escola, a comunidade em que a escola está inserida, além de elementos da cultura, relações de gênero, classe, raça e religião. Utilizando essa proposta, analisamos um banco de artigos nacionais e internacionais e selecionamos casos que oferecem bons exemplos de diferentes níveis de contexto valorizados nas pesquisas para discutir nossas análises.

\section{O contexto nos estudos da Linguagem}

O construto "contexto" possui diferentes significados oriundos de diversos campos, como Sociologia, Filosofia e Psicologia. O texto seminal de Goodwin e Duranti (1992) apresenta uma revisão sobre como essas diferentes concepções influenciaram os estudos da Linguagem, indicando a complexidade desse construto e a inviabilidade de se estabelecer uma definição precisa. A partir dessa discussão, em diálogo com contribuições mais recentes (Bloome et al., 2008, Erickson, 2008, Warriner, \& Anderson, 2016), buscamos dar visibilidade a aspectos marcadamente valorizados por diferentes tradições apresentando contexto como: ação, situação, interação social e poder.

Contexto enquanto ação refere-se aos estudos que entendem a linguagem como forma de ação sobre o mundo. Em Malinowski, um dos precursores dessa noção de contexto, a linguagem é entendida como ação prática, significando algo que vai além de uma abstração e seria um "elemento indispensável na coordenação da ação humana" (Malinowski, 1923, p. 316). Na Filosofia da Linguagem, por sua vez, encontramos indicações em sentido próximo ao que Malinowski propunha, com raízes nas contribuições de Wittgenstein.

Nesse caso, a discussão está inserida em uma tensão bem demarcada sobre como encarar o contexto entre os filósofos da linguagem, em meados do século XX. Esses estudos estavam alinhados, basicamente, a duas perspectivas. A primeira entendia a linguagem a partir de rigorosos programas formais de análise, valorizando sistemas abstratos que espelhariam a realidade da natureza, como entidade universal, independente do contexto, sob influência do movimento conhecido como Círculo de Viena. As propostas de Wittgenstein (1958) e Austin (1962), por sua vez, passaram a considerar a linguagem

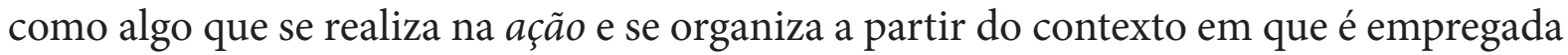
(Goodwin, \& Duranti, 1992).

A noção de contexto enquanto situação, por sua vez, tem origem no conceito de contexto de situação cunhado por Malinowski. Na obra "O problema do Significado nas Línguas Primitivas”, ele faz uma demarcação fundamental: ao invés de lidar com as línguas mortas, baseadas na estrutura dos enunciados em si mesmos, como os etnógrafos de seu tempo faziam, considera que a pesquisa exige a compreensão da linguagem somente observando diretamente situações em que os participantes a usassem em suas interações.

Estas duas noções de contexto - ação e situação - não são mutuamente exclusivas, sendo que cada perspectiva valoriza de forma mais expressiva certos aspectos da análise 
linguística. Essas noções tiveram forte influência, especialmente, para estudiosos interessados em compreender a linguagem em interações face a face (Goffman, 1967; Gumperz, 1982; Sacks, Schegloff, \& Jefferson, 1974).

Ao considerarmos perspectivas que entendem o contexto enquanto interação social, destacamos referenciais em que a tensão entre o indivíduo e o social constitui o cerne da compreensão de contexto. Em particular, destacamos as discussões das tradições soviéticas. Os estudos soviéticos, fermentados a partir da Revolução de 1917, geraram duas tradições separadas e complementares que buscaram relacionar linguagem e contexto. As escolas bakhtiniana e vygotskiana estão enraizadas nos pressupostos do materialismo dialético de Marx e oferecem, cada uma em sua área de interesse, contribuições fundamentais aos estudos linguísticos, possuindo algumas aproximações interessantes como a contraposição a visões 'individualizantes' da linguagem (Goodwin, \& Duranti, 1992).

Bakhtin (1988) contrapõem-se ao pensamento de Saussure e dos filólogos que estudavam a linguagem como sistema imutável e como consequência da consciência individual, negligenciando o contexto. Paralelamente, Vigotski (2007), contrapõese ao pensamento que entendia o desenvolvimento da linguagem como um processo controlado pela maturação orgânica individual, sem destaque à natureza social desse processo. Nesse sentido, o conteúdo contextual da linguagem, nessas tradições, reside na articulação entre o linguístico e o social.

Uma última corrente que tem influenciado grandemente as pesquisas em Linguagem é aquela que entende contexto a partir de relações de poder. Foucault é o principal responsável por contribuições consistentes e originais nesta direção (Goodwin, \& Duranti, 1992). Para ele, condições culturais inconscientes, regras e práticas governam o que as pessoas fazem com seus corpos, como se comunicam, como sentem desejo ou medo e, essencialmente, como o discurso perpassa todas essas realidades da vida humana (ver Foucault, 1986). A partir dessa concepção de discurso de Foucault, Pêcheux constrói alguns pressupostos considerados centrais que nos ajudam a compreender uma concepção de contexto na perspectiva das relações de poder. Entendendo que o discurso está relacionado ao contexto histórico-social em que é produzido, Pêcheux (1990) utiliza a noção de Condições de Produção e destaca a íntima relação entre discurso e ideologia, o que reflete como as relações de poder são construídas em uma sociedade de classes.

Como indicado por Warriner e Anderson (2016), essas discussões contribuíram de forma expressiva para compreensões posteriores do discurso em suas relações com elementos contextuais. Habermas (1984), por exemplo, fala que no cotidiano, as situações comunicativas não seguem um modelo igualitário de discurso, sendo que a regra é o poder desigual entre interlocutores, resultado da assimetria de poder na sociedade. Gee (1990), por sua vez, fala sobre o Discurso com 'D' maiúsculo para enfatizar as relações entre linguagem e poder, que se refletem no discurso cotidiano das pessoas - 'd' minúsculo - sob influência do Discurso das instituições macro sociais. Nessa mesma direção, a Análise Crítica do Discurso oferece relevantes contribuições 
sobre como os discursos podem constituir práticas de reprodução ou contestação de Discursos (Fairclough, 1992).

Consideramos que essas quatro formas de perceber contexto - ação, situação, interação social e poder - apesar de suas especificidades, podem ser relacionadas a um mesmo movimento de pesquisadores que buscaram, em diferentes épocas e devido a debates distintos, valorizar o que Goodwin e Duranti (1992) chamam de o "campo de ação em que o objeto de estudo está embebido" (p. 3).

Pensar em formas de valorizar este campo de ação ainda é alvo de tensões (Warriner, \& Anderson, 2016). Uma das discussões emergentes refere-se às relações entre o que acontece no contexto mais micro da análise linguística, ou seja, as interações entre as pessoas; e os contextos macro que seriam, por exemplo, as agendas de instituições sociais em que as pessoas estão inseridas, políticas públicas, fatores socioeconômicos, aspectos culturais etc. (Bloome et al., 2008). Pensar sobre esses níveis micro e macro, também chamados de local e global (Street, 2003), tem sido uma árdua tarefa para os estudiosos da Linguagem (Erickson, 2008).

Uma forma de estabelecer essas relações é compreender o que acontece no nível micro como se estivessem embebidos no nível macro. A ênfase nesse caso seria sobre como os processos macro têm influência sobre as interações locais (Bloome et al., 2008). Como aponta Erickson (2008), a crítica a essa abordagem top-down é que o contexto macro seria superestimado, o que levaria a um apagamento do que acontece em nível local, gerando noções distorcidas sobre como as pessoas constroem práticas de estase ou mudança social.

Uma segunda forma de estabelecer relações seria dar destaque à análise do discurso em nível micro e incorporar elementos do nível macro dos processos discursivos nessas análises (Bloome et al., 2008). Porém, a principal crítica de um modelo bottom-up é que ele pode concentrar-se "tão intimamente em características específicas da própria fala, que ignora os aspectos globais das ecologias da conversa" (Erickson, 2008, p. 108, tradução nossa).

Essas formas de relacionar contextos macro e micro nos ajudam a compreender, a princípio, como estudos da Linguagem dão visibilidade a esses elementos. Porém, Bloome e colaboradores (2008) indicam que essas perspectivas são insuficientes para contemplar a complexa relação entre diferentes níveis de contexto. Conforme representado pela Figura 1, esses autores propõem que os contextos são considerados

históricos (relacionando tanto passado com os eventos futuros), múltiplos (incluindo potenciais contradições e contextos contestados), em múltiplos níveis, assim como interativos (contextos afetam uns aos outros) (Bloome et al., 2008, p.37). 


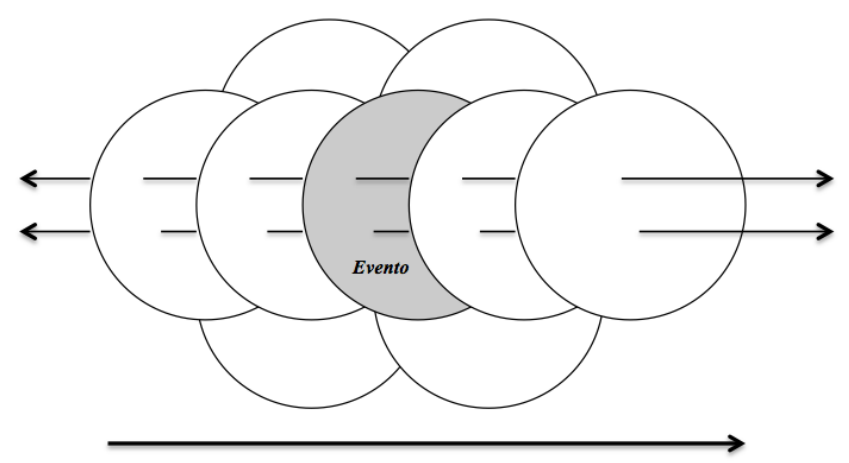

Figura 1. Representação da sobreposição entre múltiplos contextos proposta por Bloome et al. (2008, p. 38)

Essa concepção de contexto(s) oferece uma visão mais elaborada que se propõe a contemplar mais elementos do que a mera justaposição unidirecional presente nos modelos top-down e bottom-up. Dizer que contextos são históricos, por exemplo, significa que momentos vivenciados pelas pessoas no passado têm influência sobre o que está acontecendo naquele momento e, por meio da interação, essas pessoas constroem, reconstroem e figuram novos mundos, através dos quais elas "se moverão no futuro através do tempo e espaço" (Bloome et al., 2008, p. 78).

Considerar que contextos são múltiplos e se situam em múltiplos níveis, por sua vez, significa que contextos são criados e negociados no nível de um evento local representado pelas esferas conectadas temporalmente no primeiro plano da Figura 1 - e devem ser investigados em sua relação com outros eventos tanto dentro quanto fora da situação analisada conectando-os ao

Estado, outras instituições sociais dominantes, ideologias sociais e culturais, incluindo ideologias sobre linguagem, raça, gênero, competição, individualismo e o que conta como conhecimento dentro dessas instituições sociais (Bloome et al., 2008, p. 29) representado pelas esferas maiores no segundo plano da Figura 1.

Por fim, considerar que os contextos são interativos, ou seja, afetam uns aos outros, está relacionado a dois aspectos fundamentais: i) a noção de serem históricos e se influenciarem mutuamente no tempo e espaço, o que foi discutido acima; e ii) a percepção de que há relações entre um evento local e fatores macrocontextuais. Essas relações podem gerar uma diversidade de consequências situacionais, por exemplo: a dificuldade de as pessoas agirem em uma situação, o que gera construções de significados locais a partir da reprodução de elementos de nível macro; a abordagem ativa das pessoas nas circunstâncias em que se encontram, transformando, adaptando, resistindo e evitando elementos de nível macro em suas vidas cotidianas; e, em alguns casos, explicitamente minando esses elementos (Bloome et al., 2008).

Em suma, levar em conta o(s) contexto(s), a partir dessas discussões, seria enfatizar que todo evento local em sala de aula tem relações temporais com outros eventos e com fatores macrocontextuais, como as instituições sociais e relações de poder 
que perpassam o evento.

No presente artigo, as concepções de contexto discutidas oferecem um quadro conceitual que destaca a diversidade teórico-metodológica com que os estudos da Linguagem têm construído suas análises. Além disso, esta diversidade reflete a complexidade dos fenômenos estudados nas ciências Humanas e Sociais, em sua interface com múltiplas dimensões espaço temporais (Blommaert, 2015).

Especificamente nas análises que propomos, entendemos contextos como históricos, múltiplos, em múltiplos níveis e interativos, conforme proposto por Bloome et al. (2008). Por meio dessa definição, olhamos para contexto como um conjunto complexo de aspectos que se articulam àquilo que é cotidianamente construído por um grupo social. Esta noção agrega elementos significativos do campo da Linguagem, uma vez que agrega tanto concepções de contexto enquanto situação e ação, na análise das interações em nível locais, quanto noções de contexto enquanto interação social e relações de poder, ao dar visibilidade a aspectos mais amplos.

Nesse sentido, as discussões de Bloome e Green (1982) foram relevantes para que pudéssemos identificar diferentes contextos e, desse modo, propor um "olhar contextual" sobre os artigos analisados. Como discutimos, esses autores propõem que os diferentes níveis de contexto em sala de aula, desde os mais locais até os mais amplos, aparecem de forma diferente, dependendo do modo como o pesquisador "olha" para as interações em uma aula de ciências, suas opções teóricos-metodológicas destacam o papel de alguns níveis de contexto, alguns mais do que os outros, dependendo dos objetivos da pesquisa.

\section{Procedimentos Metodológicos}

O presente estudo envolveu a análise de um conjunto de artigos publicados em periódicos nacionais e internacionais. Porém, não se trata de um estudo de estado da arte porque não assume o "caráter inventariante e descritivo da produção acadêmica e científica" sobre o tema que pretendemos discutir (Ferreira, 2002, p. 258). Utilizamos um rico banco de artigos levantado por membros de nosso grupo de pesquisa como fonte de dados para a discussão que propomos. Esse levantamento foi realizado da seguinte forma: busca de artigos internacionais e nacionais; organização de informações gerais dos artigos; leitura dos artigos na íntegra; e construção de resumos estruturados.

Com relação aos artigos internacionais, a busca foi realizada no banco de dados ERIC $^{1}$ (Education Resources Information Center). Os artigos nacionais, por sua vez, foram levantados a partir de uma busca dos últimos 12 anos em periódicos classificados no extrato A do Qualis-periódicos²: Ciência \& Educação, Ensaio Pesquisa em Educação em

\footnotetext{
1 Esta base de dados do Institute of Education Sciences do Ministério da Educação dos Estados Unidos, criada em 1964 está disponível no Portal CAPES, tendo amplo reconhecimento da comunidade científica internacional da área da educação e apresentando uma política clara e consolidada para seleção de materiais. Fornece uma extensa base de dados bibliográfica, cerca de 1,5 milhões de arquivos, disponível em uma plataforma com ferramentas de busca para uso de educadores, pesquisadores e público em geral. Consulta em: https://eric.ed.gov/

2 Sistema usado para classificar a produção científica dos programas de pós-graduação brasileiros no que se refere aos artigos publicados em periódicos científicos. Consulta em: http://www.capes.gov.br/avaliacao/instrumentosde-apoio/classificacao-da-producao-intelectual
} 
Ciências, Investigações em Ensino de Ciências, Revista Brasileira de Pesquisa em Educação em Ciências. Todos os artigos que faziam referência ao nível de ensino dos anos iniciais do Ensino Fundamental e investigam interações discursivas foram selecionados em um primeiro momento. Para isso, usamos as seguintes palavras-chave: Elementary School, Early Years, Science Education, Discouse e Discursive Interactions.

Obtivemos um conjunto de 56 estudos internacionais e 55 nacionais que investigam interações discursivas em salas de aula nos anos iniciais. Em um segundo momento, dados preliminares foram lançados em planilhas com as seguintes informações: título do artigo, autores, ano da publicação, periódico, resumo, natureza do estudo (empírica ou teórica), temática na área de Educação em Ciências, disciplina (Física, Química, Biologia, Ciências ou outro) e comentários do leitor.

Desde então, esses artigos têm sido lidos na íntegra. Até então, foram lidos 34 artigos internacionais e 22 nacionais. Em um terceiro momento, após a leitura desses 56 estudos, produzimos tabelas com resumos estruturados para cada artigo. A construção dos resumos utilizou categorias semelhantes àquelas classicamente utilizadas em artigos de revisão, conforme indicado por Pinhão e Martins (2009): contexto acadêmico do estudo (filiação teórico-metodológica, por exemplo), objetivos, informações sobre os participantes e o contexto instrucional, informações sobre o desenho de pesquisa e métodos, principais resultados, conclusões e implicações educacionais.

Todos os estudos foram desenvolvidos com turmas dos anos iniciais do EF. Assim, nossas análises estão delimitadas pelo universo da pesquisa neste nível de ensino. Porém, não é nosso objetivo neste artigo dar enfoque às especificidades deste nível de ensino. Nosso intuito, ao discutir como compreender o contexto nessas pesquisas, é dar visibilidade a uma forma de desenvolver um olhar sensível ao contexto. Utilizamos os estudos sobre anos iniciais como exemplo para discutir nossa proposta. Desse modo, cabe uma distinção relevante no presente artigo: os resultados que apresentamos quanto ao levantamento de artigos e posterior análise se referem apenas aos estudos dos anos iniciais do EF e não é nossa pretensão generalizar esses achados. Porém, nossa proposta é a de que esse "olhar contextual" possa ser adotado para refletir sobre qualquer estudo interessado em investigar interações discursivas em aula de ciências, independentemente do nível de ensino.

Posteriormente, um passo em nossas análises envolveu identificar quais tipo(s) de contexto estava(m) sendo valorizado(s) em cada artigo. A partir dessas noções de Bloome e Green (1982), entendemos que na sala de aula de ciências, há uma diversidade de contextos que se sobrepõem e o pesquisador pode dar maior ou menor visibilidade a um ou outro nível de contexto.

Em nosso levantamento inicial, produzimos uma categorização que buscou enquadrar o banco de artigos que analisamos nos diferentes níveis de contexto propostos por Bloome e Green (1982). Desse modo, adicionamos aos resumos estruturados uma coluna com comentários sobre os diferentes níveis de contexto que consideramos como mais valorizados em cada estudo. Porém, com o aprofundamento nas análises, 
percebemos a complexidade desse processo. Alguns estudos valorizavam mais de um nível de contexto, ou então, ofereciam elementos de certo nível com maior ou menor ênfase do que outros. Além disso, essa categorização de caráter mais quantitativo levou a um certo apagamento das peculiaridades de cada pesquisa, o que inviabilizou uma discussão mais consistente em torno do construto contexto nos estudos.

Ao invés de um estudo baseado nas frequências de cada tipo de contexto presente nos 56 artigos analisados, corpus inicial da análise, entendemos que seria mais relevante para a área de EC apresentar uma análise com um menor número de estudos, mas com uma discussão mais profunda sobre como o contexto 'aparece' em cada um deles. O critério para a seleção de artigos foi abranger ao máximo a diversidade de formas como pesquisadores tem dado maior ou menor destaque a certos contextos na construção de suas investigações. Este critério é comumente utilizado para seleção de participantes em pesquisas de natureza qualitativa (Creswell, 2007). Portanto, não buscamos uma representatividade numérica destas formas de contemplar contextos, pois há certos contextos que são expressivamente mais valorizados na maioria dos artigos, enquanto outros são bastante escassos. O que fizemos foi identificar os contextos valorizados nos 56 artigos e, posteriormente, escolher um exemplo de cada um dos diferentes níveis de contexto identificados neste corpus inicial. Isso gerou um conjunto de 8 artigos, utilizados em nossa discussão sobre como construir um "olhar contextual" ao ler estudos sobre interações discursivas.

\section{Níveis de contexto em análises de interações discursivas nos anos iniciais do Ensino Fundamental}

Bloome e Green (1992) apresentam um modo de analisar estudos sobre a prática de leitura em sala de aula que orienta o olhar do leitor a identificar diferentes níveis de contexto que os pesquisadores valorizam através de suas metodologias e análises. Esses níveis são caracterizados a partir de elementos mais locais, ou seja, aquilo que está mais voltado para o que acontece especificamente no espaço da sala de aula, como os contextos em nível instrucional, estrutural, temático e intrapessoal; e de elementos mais globais (ou não-locais), ou seja, aquilo que vai além das paredes da sala de aula como os contextos em nível institucional, comunitário, social e cultural.

\section{Contexto Instrucional}

Um primeiro nível de contexto discutido por Bloome e Green (1982) é o contexto instrucional. Esse nível de contexto é ilustrado pelos autores a partir de um estudo em que, para entender qual seria a melhor abordagem para promover a aprendizagem dos estudantes, analisou-se o discurso de 11 professores diferentes em um evento em que eles trabalhavam um mesmo texto escrito com suas turmas, uma narrativa.

Os resultados sugerem que, uma vez que todos os professores usavam padrões de interação similares, a variação em como as crianças compartilhavam informações da narrativa não poderia ser associada a estes padrões em si, mas sim à sequência em 
que estes padrões ocorriam. Quando professores inseriam questões durante a explicação do texto, os estudantes foram capazes de retomar mais elementos da história e das discussões realizadas anteriormente. Quando o professor explicou o texto e deixou todas as questões para o final, os estudantes tiveram maior dificuldade em compartilhar o que haviam compreendido da narrativa.

Neste caso, a pesquisa deu visibilidade ao contexto instrucional da prática de leitura, uma vez que a ênfase de sua análise foi sobre o papel de uma tarefa de leitura de texto. Ou seja, há uma relação direta que a análise estabelece entre uma determinada tarefa instrucional e seus efeitos sobre a aprendizagem de certa prática em sala de aula. Não houve preocupação, por exemplo, com as rotinas de leitura em que cada turma estava inserida ao longo do ano, ou se aquele tipo de prática de conduzir as atividades de leitura era recorrente na prática de cada um dos professores.

Parte significativa dos estudos na área de Educação em Ciências que analisamos valorizam esse nível de contexto. Um exemplo bastante ilustrativo é o trabalho de Colombo Junior, Lourenço, Sasseron e Carvalho (2012). Nesse estudo, os autores analisam interações discursivas para compreender como estudantes de sete e oito anos de idade argumentam durante uma atividade de conhecimento físico. Mais especificamente, os autores analisam como as crianças resolviam o "problema da cestinha", uma atividade cujo objetivo é colocar uma bolinha em um trilho para que caia dentro da cestinha. Espera-se, com essa atividade, que os estudantes concluam que para acertar a cestinha, deve ser considerada a posição da bolinha no trilho, o que fornece elementos para construção do conceito de transformação de energia. Os autores utilizam as interações que acontecem entre as crianças para fazer a atividade, para reunir dados e analisar a construção de seus argumentos. Os autores afirmam que "quando os alunos começam a agir sobre o material, se familiarizam com o experimento e começam a testar suas hipóteses e observar evidências" (p. 498). Esse trecho é ilustrativo do modo como a análise foi construída: há o estabelecimento de relações diretas entre o que se faz na atividade proposta (agir sobre o material) e as consequências instrucionais para a aprendizagem de ciências (testar hipóteses, observar evidências). Para tais relações, Colombo Junior et al. (2012) utilizam dados do discurso das crianças para sustentar suas afirmações.

Desse modo, o estudo valoriza o contexto instrucional, uma vez que estabelece paralelos entre as variações no modo como o grupo construiu suas discussões e a tarefa que foi proposta ao grupo naquele momento: o problema da cestinha. Além disso, outra evidência da valorização do contexto instrucional é que as informações usadas pelos autores estavam relacionadas àquilo que foi observado naquele momento no tempo e no espaço. Ou seja, o leitor não sabe se esse tipo de metodologia era recorrente na turma, se foi uma novidade, ou se a professora costumava estimular discussões de grupo em sua prática pedagógica. A análise está pautada no que uma atividade específica, em nível de um evento, tem a informar. Evidentemente, não significa que esse tipo de estudo não reconheça a presença de outras dimensões do contexto em sala de aula. Antes, entendemos que os diversos contextos estão inter-relacionados e, quando um analista 
valoriza um nível de contexto, opta-se por dar destaque a uma forma específica de olhar os dados.

No estudo de Colombo Junior et al. (2012), por exemplo, é valorizado também o modo como os professores conduziram a atividade e não apenas a atividade em si mesma, o que corresponde a outro nível de contexto mais amplo do que a atividade aplicada. $\mathrm{O}$ artigo oferece afirmações que indicam esse destaque, por exemplo:

[...] é importante notar que os professores apresentam o problema e tomam o cuidado de não dar as respostas [...] Desta maneira, ele já oferece possibilidade aos alunos para que possam construir hipóteses" (p. 498).

Ou seja, a forma de conduzir a atividade também tem influência nas análises do estudo, mas não é o enfoque central. Como destacamos, o maior destaque foi dado às características que uma atividade de conhecimento físico possui e seus impactos na argumentação dos alunos, o que nos leva a afirmar que o estudo valoriza de modo mais expressivo o contexto instrucional.

\section{Contexto da Sala de Aula: níveis estrutural, temático e intrapessoal}

Outro contexto discutido por Bloome e Green (1982) é um nível de contexto da sala de aula e se refere àquilo que acontece em uma turma ao longo do tempo. Apesar de ser algo semelhante ao contexto instrucional, esse nível é distinto. O contexto instrucional, como discutimos, busca captar um momento específico de uma prática escolar - uma tarefa - e seus desdobramentos em processos de aprendizagem. O contexto da sala de aula, por sua vez, seria algo mais amplo.

A partir da interpretação de Bloome e Green (1982), o contexto da sala de aula pode ser entendido a partir de três pontos de vista: estrutural, temático e intrapessoal. Estudos que se dedicam a compreender o contexto estrutural dão enfoque às relações entre as tarefas desenvolvidas em sala de aula e seus efeitos na sala de aula. Um exemplo oferecido pelos autores é o de uma pesquisa que indicou como o modo de estruturação de tarefas de leitura tinha influência sobre as interações em sala de aula. Certas atividades eram organizadas para dar maiores oportunidades de interação aluno-aluno, o que teve impactos positivos sobre o desenvolvimento da prática de leitura. Nesse caso, destacamos que a análise corresponde a um olhar distinto do contexto em nível instrucional, pois não foi restrita às consequências geradas por uma única tarefa, mas por um conjunto de atividades e seus desdobramentos.

Para ilustrar como esse nível de contexto é valorizado na área de Educação em Ciências, selecionamos o estudo de Naylor, Keogh e Downing (2007). Os autores examinaram a influência do uso de cartoons e trabalhos em grupo sobre o modo como as crianças participavam e discutiam em aulas de ciências. O estudo foi realizado com crianças de dez anos de idade em sete turmas. Em algumas turmas desenvolveram-se atividades recorrentes utilizando cartoons com questionamentos acerca de conceitos científicos ao longo de um ano. Por exemplo: um cartoon questionava se duas sombras sobrepostas seriam mais escuras do que apenas uma, o que era seguido de discussões 
acerca da questão. Além disso, as atividades foram organizadas de diferentes formas: em algumas turmas, os cartoons eram discutidos em pequenos grupos, e em outras, com a turma toda.

Os resultados estabelecem relações entre o uso de cartoons e a frequência e complexidade das discussões nas turmas. Nas turmas em que foram introduzidas essas atividades, houve maior tempo gasto pelas crianças em discussões e observou-se níveis progressivamente mais complexos na elaboração de argumentos nas interações. Além disso, ao estabelecer comparações entre as formas de organização das turmas, as análises indicaram que nas discussões em grupo houve uma maior tendência de os estudantes buscarem entendimentos comuns, ao invés de tentar provar que o colega estava errado, como ocorria frequentemente nas discussões com a turma toda.

$\mathrm{Ou}$ seja, valorizar o contexto estrutural está relacionado à investigação sobre como o uso de uma atividade específica influencia as aulas de ciências ao longo do tempo. No caso do estudo de Naylor et al. (2007), a introdução de cartoons e a organização das turmas em grupos teve impacto sobre o modo como as crianças participavam das discussões e argumentavam ao longo do tempo de aplicação dessas atividades. Apesar de não ser o objetivo deste artigo, destacamos que esse nível de contexto foi expressivamente identificado na maioria das pesquisas presentes em nosso banco de dados.

Bloome e Green (1982) também indicam que alguns estudos que valorizam o contexto em nível da sala de aula dando enfoque à orientação do professor sobre como desenvolver a leitura com crianças, o que foi chamado de contexto temático. Os autores apresentam um estudo como exemplo para esse nível de contexto. Nessa pesquisa há uma análise sobre como crianças encaravam erros de leitura de forma diferente, dependendo da orientação que o professor adota no ensino dessa prática. Duas formas de ensinar leitura foram comparadas: meaning emphasis e word-by-word decoding emphasis). Na primeira abordagem, os professores tendem a esperar que os próprios estudantes percebam e corrijam o erro. Os alunos desses professores, por sua vez, tendem a desenvolver práticas de leitura que seguem essa orientação, agindo com maior naturalidade quando eventos de erro acontecia.

Esse tipo de estudo, que dá maior visibilidade ao modo como o professor conduz as aulas, também foi expressivamente identificado nos artigos que analisamos. A pesquisa de Monteiro e Teixeira (2004), por exemplo, valoriza elementos de contexto em nível temático. Esses autores analisaram a prática de três professoras, especificamente, ao desenvolverem atividades experimentais e subsequentes discussões em diferentes turmas de crianças de nove anos de idade. Duas dessas professoras adotaram orientações semelhantes: conduziram discussões mais diretivas e pouco dialógicas, como se estivessem seguindo um roteiro do que consideravam mais importante para que os alunos chegassem à "resposta certa". A outra professora apresentava uma orientação mais híbrida ao conduzir as discussões orais. Ora mais diretiva, ora mais dialógica, a professora usava informações que as crianças expunham para dar prosseguimento às discussões sem deixar de oferecer alguns direcionamentos. 
Essas duas diferentes formas de conduzir as aulas tiveram implicações sobre o engajamento das crianças nas aulas de ciências. Nas duas primeiras turmas, os autores entendem que a existência desse roteiro mental seguido de forma rígida pelas professoras dificultou discussões mais livres dos alunos, o que impediu maior refinamento em suas discussões e levou a uma participação menos expressiva. Por outro lado, a terceira turma foi mais participativa e capaz de desenvolver discussões mais consistentes. Nesse caso, fica clara a diferença do contexto temático para os contextos instrucional e estrutural é que: o enfoque das análises não recai sobre as atividades em si ou como são relacionadas/ organizadas, mas sobre como o professor conduz tais atividades e sua influência sobre os processos de aprendizagem.

Os estudos discutidos até aqui oferecem uma visão do que acontece no campo interpessoal da sala de aula. Bloome e Green (1982), porém, indicam que no contexto de sala de aula alguns estudos valorizam o nível intrapessoal. Esses estudos dão enfoque às orientações pessoais que os alunos dão às atividades de leitura, o que pode influenciar suas performances nessa prática. Um exemplo oferecido pelos autores é o de um estudo que caracteriza a leitura de dois alunos em uma mesma turma. Algumas características descritas foram: o que esses dois alunos escolhiam para ler, o que faziam após o momento de leitura, as habilidades de leitura que possuíam e como essas habilidades mudavam dependendo da audiência que os ouvia, etc. Essas características foram analisadas e relacionadas ao modo como individualmente cada um desses alunos construiu diferentes formas de engajamento na prática de leitura.

Em nosso levantamento, os estudos com esse tipo de enfoque foram escassos. A pesquisa de Bricker e Bell (2014) nos pareceu interessante para ilustrar o contexto em nível intrapessoal. O objetivo dos autores foi investigar como experiências de uma aluna através de espaços, atividades, grupos sociais e tempo resultaram em aprendizagem de ciências, desenvolvimento de expertise e identificação.

Para isso, os autores acompanharam uma mesma criança enquanto cursava o $3^{\circ}$, $4^{\circ}$ e $5^{\circ}$ anos na escola. Assim, as interações discursivas estabelecidas pela aluna nas aulas de ciências foram relacionadas a experiências vivenciadas por ela em outros espaços, como por exemplo, as visitas à casa da avó, onde brincava de fazer misturas com o primo; o interesse pelo kit de perfumaria que ganhou da mãe; as idas ao dentista, a visita aos museus de Arqueologia e Paleontologia; as discussões com a mãe sobre como alimentar seu cachorro de estimação. Todas essas vivências eram individuais daquela aluna e isso gerou impactos sobre a aprendizagem de ciências em sala de aula, indicando que o contexto intrapessoal ganhou destaque neste estudo. As análises indicaram que a aluna utilizou essas vivências posicionando-se de duas formas distintas ao participar das aulas de ciências: como aprendiz e como colaboradora dos colegas. $\mathrm{O}$ papel de colaboradora emergia especialmente em momentos de trabalho direto com os pares.

Portanto, um nível de contexto valorizado nesse estudo é o contexto intrapessoal, uma vez que, as análises dos autores deram visibilidade àquilo que uma aluna construía em aulas de ciências a partir de suas vivências pessoais. 


\section{Algumas considerações até aqui...}

Entendemos que os níveis de contextos discutidos até aqui, apesar de caracterizados de forma isolada, são parte de um mesmo contexto da sala de aula e estão profundamente relacionados. Nesse sentido, identificamos diversos estudos que deram visibilidade a mais de um nível de contexto em suas análises. Por exemplo, alguns construíram análises que valorizavam tanto o papel de um conjunto de atividades sobre a aprendizagem de ciências (nível estrutural), quanto a influência da forma como o professor desenvolve as atividades (nível temático).

Mesmo não se tratando de um artigo de revisão, é relevante destacar que identificamos um predomínio das pesquisas com enfoque nos níveis instrucional e da sala de aula. Porém, Bloome e Green (1982) indicaram também estudos que trouxeram à tona outros fatores contextuais que foram além do ambiente da sala de aula e buscaram estabelecer relações com a instituição, comunidade, sociedade e cultura em que os estudantes estavam inseridos. À medida que buscamos identificar estudos na área de EC que valorizassem essas escalas mais amplas de contexto, nos deparamos com uma maior escassez de produções.

Isso não significa que entendemos que esse maior foco nos contextos voltados para a sala de aula seja um problema de nossa área de pesquisas. Na verdade, esse nível de contexto é fundamental para nós, uma vez que a área de EC, independentemente dos diferentes objetivos e métodos, tem como aspecto comum o interesse pelos processos de ensino e aprendizagem de ciências. Logo, o que acontece na sala de aula de ciências e suas influências sobre esses processos serão sempre valorizados, o que é extremamente positivo.

A crítica é no sentido de responder à demanda apresentada em nossa introdução, que diz respeito à necessidade de desenvolver análises capazes de valorizar aspectos contextuais mais amplos. Os exemplos que apresentamos nas próximas seções nos ajudam a compreender como pesquisadores em EC têm feito esse movimento e como esse olhar analítico é capaz de gerar novos e interessantes percepções sobre o que acontece na sala de aula de ciências.

\section{Contexto Institucional/Curricular}

A partir das propostas de Bloome e Green (1982), esse nível de contexto refere-se às relações entre os processos de leitura na sala de aula e a influência de fatores institucionais. Fatores institucionais podem ser entendidos como práticas institucionalizadas na escola ou elementos relacionados ao currículo. Um estudo citado pelos autores nessa perspectiva apresentou dados sobre as dificuldades que diferentes turmas apresentavam em leitura. Dentre os resultados, os pesquisadores apontaram que um fator impactante foi o tempo que cada instituição dedicava às atividades de leitura, sendo que o grupo que passava menos tempo com o professor de leitura apresentava as maiores dificuldades. Ou seja, a leitura foi relacionada a um fator institucional e curricular: o tempo usado em atividades de leitura. 
Na área de Educação em Ciências um exemplo interessante desse tipo de discussão é apresentado por Enfield, Smith e Grueber (2008). Esse estudo buscou investigar a introdução de práticas epistêmicas ${ }^{3}$ em aulas de ciências a partir da análise comparada de duas propostas curriculares distintas. Uma mesma turma de crianças de oito anos de idade foi investigada em diferentes momentos. As crianças foram acompanhadas durante um ano e aprenderam sobre a relação entre força e movimento dos corpos no primeiro semestre, e sobre o crescimento das plantas no segundo. $\mathrm{O}$ mesmo professor desenvolveu todas as aulas, porém em cada semestre foi adotada uma proposta curricular distinta ${ }^{4}$.

A proposta curricular do primeiro semestre trazia indicações claras sobre o papel de cada prática epistêmica desenvolvida, o que deveria ser explicitamente trabalhado pelo professor ao longo das aulas. No conjunto de aulas do segundo semestre, por outro lado, houve grande concentração de procedimentos relacionados à coleta de dados e observação, baseadas em atividades hands on, sem, no entanto, haver perguntas orientadoras para cada investigação.

Para os autores, a primeira proposta ofereceu mais oportunidades para que os alunos se engajassem na construção do raciocínio científico e desenvolvessem noções mais consistentes sobre a produção de questões em aulas de ciências. A segunda proposta, por sua vez, pareceu ter maior êxito em desafiar as concepções prévias dos estudantes. Dessa forma, as orientações curriculares foram relacionadas diretamente aos modos de construir o conhecimento na sala de aula. Isso deu visibilidade a um nível de contexto mais amplo que os contextos instrucional e da sala de aula: as implicações de se utilizar uma determinada orientação curricular em aulas de ciências.

\section{Contexto Comunitário}

Outro nível de contexto descrito por Bloome e Green (1982) é o contexto comunitário. Os estudos que estabelecem relações entre a leitura e a comunidade na qual a escola está inserida valorizam esse tipo de contexto. Um exemplo dos autores envolve a leitura em uma escola de uma comunidade no Alasca. Tradicionalmente, essa comunidade associava práticas de letramento à cultura estrangeira, de modo que as pessoas que liam e escreviam eram consideradas "forasteiros", aqueles que não compartilhavam os valores do grupo. Essa visão estigmatizada de leitura e escrita gerou um impacto sobre como os estudantes dessa escola lidavam com essas práticas em sala de aula, bem como tensões entre o contexto comunitário e o contexto institucional, nesse caso, as indicações curriculares do governo.

$\mathrm{Na}$ área de Educação em Ciências, a pesquisa de Reinhart et al. (2016) é um

3 Os autores consideram como práticas epistêmicas: fazer perguntas, coletar dados, produzir descrições de observações, buscar padrões nos dados, e desenvolver o raciocínio científico.

4 A unidade sobre movimento era parte da proposta curricular do centro CCMS (The Center for Curriculum Materials in Science). Esse centro produz materiais a partir de parcerias entre instituições como, a Associação Americana para o Avanço da Ciência (AAAS) e algumas universidades (por exemplo, de Michigan e Northwestern). Já a unidade sobre as plantas era parte de uma proposta curricular desenvolvida por uma instituição privada do estado de Michigan nos Estado Unidos, a BCAMSC (The Battle Creek Area Mathematics and Science Center). 
bom exemplo para ilustrar como esse nível de contexto pode ganhar visibilidade. Esses autores acompanharam famílias dos alunos de seis turmas em uma mesma cidade. Nessa cidade já acontecia um projeto da Universidade de Harvard ${ }^{5}$, que consistia em um conjunto de atividades de ciências que deveria ser desenvolvido em família. O que foi observado é que nem todas as famílias se engajavam de forma satisfatória na realização do projeto e os autores criaram duas categorias de famílias: as muito participativas e as que participavam pouco. $\mathrm{O}$ critério para criação desses grupos foi a participação das famílias em eventos escolares ao longo de um ano e o número de visitas ao centro de ciências da cidade.

As análises sugeriram que o maior engajamento nas atividades junto à família foi um elemento importante para despertar o interesse das crianças pelas aulas de ciências e maior participação nessas aulas. Além disso, a análise das interações revelou maior expressão de comportamentos investigativos entre as crianças de famílias participativas. Em nossa interpretação, o nível de contexto comunitário ganha relevo nesse tipo de investigação. Suas análises destacaram como os membros da comunidade em que uma escola estava inserida valorizavam de modo diferenciado as ciências em seu cotidiano e na vida escolar de suas crianças, o que foi relacionado ao processo de aprendizagem de ciências desses estudantes.

Como já indicamos, identificamos estudos que dão visibilidade a mais de um nível de contexto. O artigo de Bricker e Bell (2014), que em nossa interpretação valorizam o contexto intrapessoal, também oferece muitos elementos que dão destaque ao nível comunitário. As análises desses autores, apesar de serem sobre uma única aluna, utilizaram diversos elementos da comunidade em que ela estava inserida, por exemplo: as brincadeiras de cientista que fazia com colegas e primos, as idas ao dentista e visitas a museus de ciências. Todas essas vivências foram reveladoras de como elementos presentes em sua comunidade tiveram influências sobre sua participação nas aulas de ciências e aprendizagem.

\section{Contexto social}

Outros estudos analisados por Bloome e Green (1982) buscaram dar enfoque às relações entre a prática de leitura e estruturas sociais. O objetivo dessas pesquisas foi menos no sentido de pensar sobre a instrução ou desenvolvimento individual da leitura e mais na direção de analisar fatores mais amplos do que o ambiente da sala de aula.

Os autores apresentam estudosqueestabeleceram relações entre odesenvolvimento da leitura e fatores como: estratificação social, raça, gênero, religião e poder político/ econômico. Um desses estudos, por exemplo, fez análises sobre a prática de leitura em uma turma de crianças na periferia da cidade de Chicago. Alguns desses alunos, filhos de negros e latinos, desenvolveram estratégias alternativas ao processo educacional para alcançar níveis de proficiência em leitura e ganhar o respeito do restante da turma. Ou seja, aprender a ler, nesse caso, foi relacionado a questões de poder econômico e

5 Projeto "What is complementary learning?” acessível no endereço eletrônico: http://www.hrfp.org 
segregação racial.

Para ilustrar esse tipo de perspectiva na área de Educação em Ciências, usamos o trabalho de Oliveira et al. (2012). Nesta pesquisa, as análises giram em torno de discussões sobre dilemas ambientais. Um dos dilemas foi sobre o que fazer com um veado encontrado sozinho na mata.

A análise das interações destacou embates entre alunos que adotaram posicionamentos homofóbicos com relação a um colega e outros que buscavam defendelo. Como na sociedade brasileira a palavra veado é uma expressão para homossexual, os autores indicaram que a situação gerou um ambiente de insegurança social que influenciou o modo de argumentar das crianças. Assim, ao invés de se basearem em uma racionalidade científica para construir uma resposta para o dilema, como havia ocorrido nas discussões dos dilemas anteriores, as crianças rapidamente concordaram em torno de uma resposta mais simples, tentando proteger um colega que se tornara alvo de bullying.

Em síntese, os autores usaram um fator macro social, relacionado ao machismo e homofobia, para interpretar o modo como um grupo de crianças construiu respostas na aula de ciências. Interessante destacar que em nosso levantamento de artigos, poucos estudos fizeram esse movimento de relacionar fatores sociais ao que acontece nas aulas de ciências.

\section{Contexto cultural}

Por fim, Bloome e Green (1982) discutem estudos que valorizam o contexto cultural. São pesquisas que buscam compreender como aspectos da cultura de um grupo influenciam no desenvolvimento da leitura. Um exemplo oferecido pelos autores é o de uma investigação sobre processos de leitura em uma escola de uma cidade do Alasca que possuía alunos indígenas (tribo Athabaskan).

$\mathrm{Na}$ cultura dos Athabaskan, há algumas peculiaridades com relação à prática de contação de histórias. Diferente do que acontece na cultura ocidental, existe entre os Athabaskan um processo de negociação entre a audiência e narrador. O contador da história apresenta apenas uma introdução (framework) da narrativa e a audiência tem um papel ativo na continuidade de sua construção.

Quando chegavam à escola, as crianças Athabaskan enfrentavam diversos problemas, inclusive no desenvolvimento da prática de leitura. No estudo apresentado, os autores analisaram como cinco crianças indígenas mudaram seus procedimentos de leitura ao longo do tempo, uma vez que sua prática de conduzir as narrativas era algo desvalorizado pelos colegas e professores. Dessa forma, a leitura foi relacionada a elementos culturais que estavam em choque na sala de aula investigada.

$\mathrm{Na}$ área de EC, encontramos muitas pesquisas que se voltam para aspectos da cultura, especialmente quando tratam das temáticas diversidade e minorias. Porém, nesse conjunto, foram raros os que buscavam analisar interações discursivas em sala de aula. A pesquisa de Upadhyay (2009) oferece um exemplo interessante nesse sentido. 
O autor investigou aulas de ciências em uma turma de crianças de dez anos de idade nos Estados Unidos. O grupo era constituído por brancos, negros e crianças Hmong As análises indicaram como a professora, de origem Hmong, buscava estratégias para valorizar a cultura desse grupo. Um exemplo foi o estudo sobre as plantas. A crianças Hmong recorriam de modo frequente a exemplos de jardinagem, prática importante nessa cultura e com significados de cunho espiritual.

A professora utilizou esse interesse e envolvimento dos alunos com a jardinagem para envolvê-los de forma mais ativa nas investigações sobre plantas, o que foi, segundo o autor, consequência da capacidade da professora de perceber a importância da jardinagem devido sua ligação com a cultura Hmong. Em termos de inclusão/exclusão dos estudantes, esse estudo oferece um contraste interessante com o estudo mencionado por Bloome e Green (1982) sobre leitura. Este destaca como as características de uma cultura minoritária foi subjugada na escola, o que foi responsável por estratégias de adaptação por parte das crianças dessa cultura. Por outro lado, o estudo de Upadhyay (2009) destaca como um grupo minoritário se envolveu de forma mais efetiva nas aulas de ciências, o que foi relacionado à inserção de elementos de sua cultura pela professora.

\section{Propondo um olhar descritivo}

Neste artigo, propomos uma discussão acerca do construto contexto utilizando exemplos de estudos da área de Educação em Ciências que investigam interações discursivas nos anos iniciais do Ensino Fundamental. As pesquisas que apresentamos, em caráter ilustrativo, indicam que os pesquisadores, dependendo de seus objetivos e metodologias, podem dar visibilidades a diferentes contextos ao estudar a sala de aula.

Mesmo com essa diversidade, destacamos o predomínio dos estudos que dão enfoque aos contextos nos níveis instrucional e da sala de aula. Apesar de não ser o objetivo deste artigo, gostaríamos de apontar que, dos 56 artigos que inicialmente analisamos, apenas cinco foram categorizados como estudos que estabeleceram relações com níveis de contexto mais amplos, como institucional, comunitário, social e cultural. Quatro desses estudos foram apresentados neste artigo.

$\mathrm{O}$ predomínio de estudos com enfoque instrucional pode estar relacionado à busca por uma educação de qualidade. Existe uma demanda na atualidade relacionada ao impacto que certas atividades inovadoras, abordagens ou práticas docentes têm sobre os estudantes e esse tipo de investigação é necessário para gerar indicações sobre o que deve ou o que não deve acontecer em uma 'boa' aula de ciências (Kelly, 2005, Munford et al., 2014). Kelly (2005) chama os estudos relacionados a esse tipo de enfoque de estudos normativos por estarem orientados por argumentos "baseados em pontos de vista moral e com foco em ideais ou normas que guiam a prática social” (p. 80, tradução nossa).

Concordamos com Kelly (2005) sobre a relevância de estudos desse caráter. Porém, esse mesmo autor argumenta que estudos de caráter descritivo também têm

6 Os Hmong são um grupo vietnamita. Eles tiveram que deixar sua terra natal após a guerra do Vietnã e, antes de chegarem aos Estados Unidos, viveram como refugiados na Tailândia e no Laos. 
grande importância no sentido de oferecer outros olhares que podem contribuir para um avanço da área de Educação em Ciências e um olhar mais amplo sobre os outros contextos presentes em uma sala de aula, para além do instrucional.

Ao mencionarmos estudos mais "descritivos" nos alinhamos à noção proposta por Kelly (2005) de que, para compreender a ciência na sala de aula, é preciso levar em consideração as formas como o conhecimento científico escolar éformulado, comunicado, criticado, apropriado e avaliado por um grupo social particular, considerando que este grupo possui uma história e usa a linguagem de maneira específica, inserido em determinado contexto. Estes tipos de estudo têm sido expressivamente influenciados pelos campos da Sociologia/Antropologia e têm como enfoque "as práticas efetivas de um grupo social, independentemente de se essas descrições se conformam às normas estabelecidas ou regras de comportamento" (Kelly, 2005, p. 80, tradução nossa).

Nos estudos que analisamos para construção do presente artigo, notamos que aqueles com enfoque mais normativo deram maior visibilidade aos contextos instrucional e da sala de aula. Por outro lado as pesquisas com caráter descritivo mais expressivo foram justamente aquelas que buscaram estabelecer relações com contextos em níveis mais amplos, como o social e cultural.

Propomos que as pesquisas que investigam interações discursivas em aulas de ciências explorem as potencialidades dos estudos de caráter mais descritivo. Kelly (2005), ao defender o desenvolvimento desse tipo de pesquisa, usa três argumentos. O primeiro é que o enfoque descritivo é capaz de tornar visíveis significados que membros do grupo compartilham, a partir do estudo de suas práticas sociais. Através da análise de práticas do cotidiano de um grupo, associadas a construtos do campo da pesquisa em Educação em Ciências - como por exemplo, natureza da ciência, ensino por investigação, construtivismo, atividades hands on - é possível compreender significados construídos pelo próprio grupo em aulas de ciências - por exemplo, o que conta como ensino por investigação para aquele grupo. Neste caso, o enfoque no cotidiano do grupo, e não no conteúdo instrucional das aulas, é capaz de gerar insights sobre como o próprio grupo experimenta e significa essa instrução, levando a uma reflexão sobre o significado que a comunidade científica atribui a um certo construto.

O segundo argumento de Kelly é que estudos descritivos podem nos ajudar a compreender situações que fogem ao esperado do ponto de vista instrucional, mas que estão diretamente relacionados à aprendizagem de ciências. Por exemplo, quando em função de questões colocadas por um aluno, o professor foge de seu planejamento inicial e gera uma situação "anômala", possivelmente, estimulado por interesses e intervenções dos próprios alunos.

Kelly (2005) indica que uma forma potencialmente interessante de gerar esses insights é analisar eventos em que situações "anômalas" acontecem. Ou seja, procurar situações em que há quebra das expectativas do pesquisador ou dos participantes sobre o que aconteceria em uma aula de ciências. Nestes momentos, existem grandes chances de se descrever como os próprios membros do grupo estão negociando e construindo 
certas normas e práticas, o que pode ser fundamental para o pesquisador compreender o que conta como aprender ciências ou como ciências para o grupo. Para estudantes, pessoas que estão sendo introduzidas no saber e no fazer ciências, situações anômalas podem ser indicativas de como eles estão aprendendo a participar do evento social "aula de ciências" e como se engajam em oportunidades de aprendizagem de ciências. Isto dificilmente seria percebido ou valorizado em estudos norteados por um desenho de pesquisa normativo.

O terceiro argumento de Kelly é que os estudos descritivos dão enfoque às vidas cotidianas das pessoas em situações concretas. Ao investigarmos a sala de aula de ciências orientados pela busca/construção de propostas de ensino de ciências que seriam adequadas e aplicáveis aos mais diversos contextos, podemos ignorar os limites destas propostas e também como a aprendizagem de ciências ocorre de formas variadas dentro de um conjunto de atividades instrucionais.

Kelly (2005) ilustra como a perspectiva descritiva agrega novos elementos a partir do exemplo da análise da fala de um aluno durante uma aula de ciências. Uma análise restrita ao conteúdo estrutural da fala, indicou que o estudante não dominava os conceitos abordados na aula. Porém, considerando o contexto da situação em que o estudante se encontrava, bem como o contexto do cotidiano de sua turma, uma análise descritiva foi capaz de indicar diversos elementos sobre como ele estava produzindo sentidos sobre os conceitos e que ele construíra um conhecimento coerente com o cientificamente aceito. Só foi possível visualizar esses elementos através da uma compreensão da fala do aluno à luz da história da turma nas aulas de ciências e de uma análise que considerou características contextuais da fala, por exemplo, entonação, olhares e movimentos corporais. Dessa forma, um estudo descritivo foi capaz de explorar como a aprendizagem esperada ocorre de outras formas, o que seria pouco valorizado em estudos mais normativos. Assim, estudos descritivos podem contribuir para a construção de abordagens mais inclusivas que contemplem a diversidade presente em nossas salas de aula.

Ao nos apropriarmos desta perspectiva, como alerta Kelly (2005), não se pretende propor um dualismo descritivo versus normativo nos estudos da área de Educação em Ciências. Estudos que abordam argumentos mais descritivos também estabelecem julgamentos morais em alguma medida sobre o que acontece na sala de aula. O mesmo acontece com estudos com enfoque mais normativo, que podem lançar mão de elementos descritivos. A diferença consiste na ênfase dada pelos pesquisadores às análises.

O estudo de Monteiro e Teixeira (2004), por exemplo, tem maior enfoque em argumentos normativos, mas os autores usam elementos descritivos para caracterizar as performances das três professoras investigadas. Mesmo assim, o maior enfoque normativo acontece porque o que orienta o desenho de pesquisa é justamente um julgamento sobre qual das professoras tem uma prática "melhor" e é mais capaz de fomentar interações entendidas como significativas para a aprendizagem de ciências.

Portanto, finalizamos essa discussão argumentando que uma forma de 
enfrentarmos o desafio de investigar a sala de aula de ciências com um olhar mais sensível ao contexto, seria o desenvolvimento e a valorização de estudos mais descritivos na pesquisa em EC, conforme as noções apresentadas por Kelly (2005). Entendemos que a dimensão normativa das pesquisas na área de Educação em Ciências, reflete seu papel fundamental na construção de uma educação de qualidade e no desenvolvimento de alternativas para que essa qualidade esteja presente nos espaços escolares. Porém, a dimensão mais descritiva oferece possibilidades para que o pesquisador compreenda o que acontece em sala de aula de ciências sob outras perspectivas, concebendo processos de ensino e aprendizagem mais voltados para as percepções daqueles que vivenciam esses processos, ou seja, os próprios estudantes e seus professores. Além disso, a perspectiva mais descritiva tem potencialidades de valorizar outros contextos que vão além das "paredes da sala de aula" e que também têm forte influência sobre o que é construído pelos estudantes ao aprenderem ciências. Assim, revelando a articulação entre descritivo e normativo, podemos ampliar os horizontes de uma educação científica de excelência.

\section{Agradecimentos}

O presente estudo foi desenvolvido graças a recursos da universidade pública e financiamento do CNPq, amplamente ameaçados pela severa crise política e moral que vem restringindo os horizontes da Educação, Ciência e Tecnologia no Brasil.

Agradecemos à profa. Dra. Rosária Justi pelas valiosas contribuições na disciplina “Tendências em Educação em Ciências” do Programa de Pós-gradução em Educação da Universidade Federal de Minas Gerais. Agradecemos também aos colegas do grupo de pesquisa Êmico pelas constantes discussões acerca do(s) "contexto(s)" e sua relevância em nossas análises.

\section{Referências}

Austin, J. L. (1962). How to do Things with words. New York: Oxford University Press.

Bakhtin, M. (1988). Marxismo e filosofia da linguagem. São Paulo: Hucitec.

Bennett, J., Lubben, F., \& Hogarth, S. (2007). Bringing science to life: a synthesis of the research evidence on the effects of contextbased and STS approaches to science teaching. Science Education, 91(3), 347-370. https://doi.org/10.1002/sce.20186

Blommaert, J. (2015). Chronotopes, Scales, and Complexity in the Study of Language in Society. Annual Review of Anthropology, 44, 105-116. https://doi.org/10.1146/annurevanthro-102214-014035

Bloome, D., \& Green, J. (1982). The social contexts of reading: Multidisciplinary perspectives. In B. Hutson (Ed.). Advances in reading/language research, Greenwich: JAI Press. 
Bloome, D., Carter, S. P., Christian, B. M., Madrid, S., Otto, S., Shuart-Faris, N., Smith, M. (2008). Discourse Analysis in Classrooms: Approaches to language and literacy research. Nova York: Teachers College Press.

Bricker, L. A., \& Bell, P. (2014). "What Comes to Mind When You Think of Science? The Perfumery!": Documenting science-related cultural learning pathways across contexts and timescales. Journal of Research in Science Teaching, 51(3), 260-285. https://doi. org/10.1002/tea.21134

Colombo Junior, P. D., Lourenço, A. B., Sasseron, L. H., \& Carvalho, A. M. P. (2012). Ensino de Física nos anos iniciais: análise da argumentação na resolução de uma Atividade de Conhecimento Físico. Investigações em Ensino de Ciências, 17(2), 489-507.

Creswell, J. W. (2007). Qualitative inquiry and research design: Choosing among five approaches ( $2^{\text {nd }}$ ed.). Thousand Oaks., CA: Sage.

Enfield M., Smith, E. L., \& Grueber, D. J. (2008). “A Sketch Is Like a Sentence”: Curriculum Structures That Support Teaching Epistemic Practices of Science. Science Education, 92(4), 608-630. https://doi.org/10.1002/sce.20252

Erickson, F. (2008). Talk and Social Theory: Ecologies of Speaking and Listening in Everyday Life. Cambridge: Polity Press.

Fairclough, N. (1992). Discourse and social change. Cambridge: Polity Press.

Ferreira, N. S. A. (2002). As pesquisas denominadas "estado da arte". Educação e Sociedade, 23(79), 257-272.

Foucault, M. (1986). A Arqueologia do saber. Rio de Janeiro: Forense.

Gee, J. (1990). Social linguistics and literacies: ideologies in discourses. Basingstoke: The Falmer Press.

Gilbert, J. (2014). Science education through contexts: Is it worth the effort? In D. M. Watts (ed.). Debates in Science Education (pp.145-157). Rotterdam: Sense.

Goffman, E. (1967). Interaction ritual, essays on face-to-face behavior. New York: Doubleday.

Goodwin, C., \& Duranti A. (1992). Rethinking context: Language as an interactive phenomena. Cambridge: Cambridge University Press.

Gumperz, J. (1982). Discourse Strategies. Cambridge: Cambridge University Press.

Habermas, J. (1984). The theory of communicative action. Boston: Beacon Press.

Kelly, G. J. (2005). Discourse, description, and science education. In R., Yerrick, \& W. M., Roth (eds.). Establishing Scientific Classroom Discourse Communities: Multiple Voices of Research on Teaching and Learning (pp. 79-108). Mahwah: Lawrence Erlbaum Associates. 
Lin, T., Lin, T., \& Tsai, C. (2014). Research Trends in Science Education from 2008 to 2012: A systematic content analysis of publications in selected journals. International Journal of Science Education, 36(8), 1346-1372. https://doi.org/10.1080/09500693.2013 .864428

Lemke, J. L. (2001). Articulating Communities: Sociocultural Perspectives on Science Education. Journal of Research on Science Teaching, 38(3), 296-316. https://doi. org/10.1002/1098-2736(200103)38:3<296::AID-TEA1007>3.0.CO;2-R

Malinowski, B. (1923). The problem of meaning in primitive languages. In C. K. Ogden, \& I. A. Richards. The Meaning of Meaning (pp. 296-336). London: Kegan Paul.

Manz, E., \& Renga I. P. (2017). Understanding how teachers guide evidence construction conversations. Science Education, 101(4), 584-615. https://doi.org/10.1002/sce.21282

Monteira, S. F., \& Jiménez-Aleixandre, M. P. (2015). The Practice of Using Evidence in Kindergarten: The Role of Purposeful Observation. Journal of Research in Science Teaching, 52(6), 1232-1258. https://doi.org/10.1002/tea.21259

Monteiro, M. A. A., \& Teixeira, O. P. B. (2004). Uma análise das interações dialógicas em aulas de ciências nas séries iniciais do ensino fundamental. Investigações em Ensino de Ciências, 9(3), 243-263.

Mortimer, E. F., Scott, P., Amaral, E. M. R., \& El-Hani, C. N. (2014). Conceptual profiles: theoretical methodological bases of a research program. In E. F. Mortimer \& C. N. ElHani (ed.), Conceptual profiles: a theory of teaching and learning scientific concepts (pp. 3-33). Dordrecht: Springer.

Munford, D., Souto, K. C. N., \& Coutinho, F. D. (2014). A etnografia de sala de aula e estudos na educação em ciências: Contribuições e desafios para investigações sobre o ensino e a aprendizagem na educação básica. Investigações em Ensino de Ciências, 19(2), 263-288.

Naylor, S., Keogh, B., \& Downing, B. (2007). Argumentation and Primary Science. Research in Science Education, 37(1), 17-39. https://doi.org/10.1007/s11165-005-90025

Oliveira, A. W., Akerson, V. L., \& Oldfield, M. (2012). Environmental Argumentation as Sociocultural Activity. Journal of Research in Science Teaching, 49(7), 869-897. https:// doi.org/10.1002/tea.21020

Pechêux, M. (1990). As condições de produção do discurso. In F. Gadet, \& T. Hak. (org.) Por uma análise automática do discurso: Uma introdução à obra de Michel Pêcheux. São Paulo: Editora da UNICAMP. 
Pinhão, F., \& Martins, I. (2009). A análise do discurso e a pesquisa em ensino de ciências no brasil: um levantamento da produção em periódicos entre 1998 e 2008. In VII Encontro Nacional de Pesquisa em Ensino de Ciências. Anais do VII ENPEC, Florianópolis: ABRAPEC. Recuperado de http://posgrad.fae.ufmg.br/posgrad/viienpec/pdfs/518.pdf

Ramsden, J. (1997). How does a context-based approach influence understanding of key chemical ideas at 16+? International Journal of Science Education, 19(6), 697-710. https://doi.org/10.1080/0950069970190606

Reinhart, M., Bloomquist, D., Strickler-Eppard, L., Gilbert, C. M. C. A., Kaderavek, J., \& Molitor, S. C. (2016). Taking Science Home: Connecting Schools and Families Through Science Activity Packs for Young Children. School Science and Mathematics, 116(2), 3-16. https://doi.org/10.1111/ssm.12152

Rex, L., Green, J., \& Dixon, C. (1998). What counts when context counts? The uncommon 'common' Language of Literacy Research. Journal of Literacy Research, 30(3), 405-433. https://doi.org/10.1080/10862969809548006

Ryu, S., \& Sandoval, W. A. (2012). Improvements to Elementary Children's Epistemic Understanding from sustained Argumentation. Science Education, 86(3), 488-526. https://doi.org/10.1002/sce.21006

Sacks, H., Schegloff, E., \& Jefferson, G. (1974). A simplest systematics for the organization of turn-taking for conversation. Language, 50(4), 696-735. https://doi. org/10.2307/412243

Upadhyay, B. (2009). Teaching Science for Empowerment in an Urban Classroom: A Case Study of a Hmong Teacher. Equity \& Excellence in Education, 42(2), 217-232. https://doi.org/10.1080/10665680902779366

Vygotsky, L. S. (2007). A Formação Social da Mente: o desenvolvimento dos processos psicológicos superiores. São Paulo: Martins Fontes.

Warriner, D., \& Anderson, K. T. (2016). Discourse Analysis in Educational Research. In K. King, Y. Lai, \& S. May. Research Methods in Language and Education (pp. 1-12), $3^{\text {rd }}$ Ed. Switzerland: Springer.

Wittgenstein, L. (1958). Philosophical Investigations. Blackwell Publishing. 
Luiz Gustavo Franco

http://orcid.org/0000-0002-1009-7788 Universidade Federal de Minas Gerais

Faculdade de Educação

Belo Horizonte, Brasil luiz.gfs@hotmail.com

Danusa Munford

[- http://orcid.org/0000-0001-7071-4904 Universidade Federal de Minas Gerais Faculdade de Educação Belo Horizonte, Brasil danusamun@gmail.com

Submetido em 29 de Maio de 2017 Aceito em 19 de Novembro de 2017 Publicado em 27 de Março de 2018 